\title{
A Unificação de Princípios na Constituição Federal de 1967
}

CLENICIO DA SILVA DUARTE

Consultor Jurídico do DASP

SUMÁRIO: 1. O Estado federal e a descentralização como fenômeno intrínseco a essa forma de Estado, nos primórdios de sua criação. O recuo centralizador como fenômeno universal decorrente, em grande parte, da revolução tecnológica posterior à segunda guerra mundial, o que acarretou, entre outras medidas, a revisão da Teoria Política. 2. A descentralização, para tornar-se eficaz, impõe desenvolvimento econômico e cultural. 3. A unificação de princípios constitucionais como resultante da centralização, o que determinou acentuada restrição à autonomia dos Estados-membros e Municípios em benefício da dinamização da gestão da coisa pública. 4. O cerceamento da livre estipulação constitucional dos Estados-Membros e dos Municípios como decorrência da unificação de princípios. 5. A incorporação imediata de princíplos constitucionais, quer expressamente determinada, quer implicitamente, feita a necessária adaptação, na forma do art. 200, caput, da Constituição Federal, na redação em vigor. 6 . Relação dos princípios expressamente dirigidos aos Estados, aplicávels igualmente, no que couberem, aos Municípios. 7. Os princípios implicitos, carentes de adaptação. 8. Conclusão.

1. A evolução do nosso Direito Constitucional a partir da república, - no que segue, aliás, uma tendência universal hodierna, - se tem feito no sentido de uma maior centralização, quer no que tange, no Estado federal, à restrição de autonomia dos Estados-membros, quer no que concerne, na própria União e nos Estados-membros, a uma verdadeira hegemonia do Executivo sobre os demais poderes. Se o conceito de federalismo pressupõe, de certo modo, o de descentralização, a conferida pelo modelo norte-americano, que tanto influiu em nossa primeira Constituição republicana, teve que sofrer, entre nós, um recuo acentuado e progressivo, quase que desfigurante, para atender não só às condições e peculiaridades brasileiras como à própria evolução social do mundo moderno, que 
vive uma autêntica revolução tecnológica, grandemente responsável pela revisão de conceitos que teve de operar-se na Teoria

A partir da revolução de 1964, verifica-se, no Direito Constitucional brasileiro, acentuada influência da Constituição francesa de 4 de outubro de 1958, seja nos atos institucionais baixados pela revolução, seja na Constituição de 1967, de modo a assegurar-se, fundamentalmente, um maior fortalecimento do Poder Executivo central, o que, num certo sentido, eram dois fenômenos diversos que levaram a um mesmo objetivo. Se, na França, foi a anarquia parlamentar que redundou num regime mutoritário, pela necessidade, como diz PAUL BASTID," 2 de "remediar a insegurança crônica do poder", no Brasil, a subversão, provocada pelo próprio Governo, sem que o Congresso houto revolucontrado um meio de coartá-la, resultou num movimenvo e da União, que estabeleceu o fortalecimento do Executio que era um em detrimento das outras unidades federadas, tica, adequar meio de, atendendo à evolução da Ciência Poll2. Se a realidade brasileira.

2. Se a descentralização, além de ser um conceito intrínseco territorial, não é é de grande valia num país de vasta extensão federadas a é menos exato que só funciona se as unidades econômico e cultural entre si proporções de desenvolvimento com que a coisa púb e têm maturidade política capaz de fazer uma administração cientificja gerida segundo os princípios de de progresso nacional.

As disparidades, nesse sentido, entre as nossas unidades
federadas e a imaturidade mais de oitenta imaturidade política, constatada ao longo de viabilidade dessa de vida republicana, demonstraram a inconcentração descentralização, aconselhando uma maior um acentuado poderes na União, com o que se determinava Municípios, lamentável teimento da autonomia dos Estados e mos do que convinhal teoricamente, mas imprescindivel em terao País.

A má utilização dos poderes conferidos às unidades fe-
deradas (Estados-mo

1 Cf. nosso artigo sob o

- Primado do Direito Administitulo $\mathrm{A}$ Concepção Moderna de Democracia e dezembro de 1967, pp. 68 e segs., e na Revista de Direito público, vol, julho a
202 e segs.

Revue Internatincipes Généraux de la Nouvelle Constitution Française, in 
republicano impunha essa restrição de autonomia, como mal menor para obviar os desmandos decorrentes de liberalidades excessivas à custa do erário e de verdadeira irresponsabilidade na gestão da coisa pública, com o desvio das altas finalidades para as quais se criou e organizou o Estado.

3. A unificação de princípios constitucionais, cerceando-se em grande escala a atividade constituinte dos Estados-membros, se redundou em indisfarçável alcance à autonomia das unidades federadas, por outro lado possibilitou maior disciplinamento e permitiu a uniformidade de postulados constitucionais, num trabalho centralizador, mas de inegável projeção científica e de sadia política de gestão da coisa pública, dinamizando-se, extraordinariamente, a máquina administrativa. ${ }^{3}$

Com a Constituição de 1967, em sua primitiva redação, impôs-se, no que coubesse, a adaptação de seus princípios aos Estados-membros, em sessenta dias, findos os quais eles se incorporariam às Cartas estaduais, mutatis mutandis, houvesse ou não ocorrido a adaptação determinada. ${ }^{4}$

Com a reforma constitucional de 1969 (Emenda Constitucional $n$ ? 1, de 17 de outubro daquele ano), a imposição é mais drástica e imediata, determinando-se, desde logo, a incorporação de suas disposições, no que coubesse, ao Direito Constitucional dos Estados, ${ }^{5}$ independentemente de qualquer ato estadual específico. ${ }^{6}$

4. Ao princípio tradicional da liberdade de estipulação dos Estados-membros, que só estavam adstritos em suas Constituições à obediência aos postulados gerais atinentes à forma de governo, à temporariedade dos mandatos, à independência e harmonia dos poderes e outros imprescindiveis ao regime democrático ${ }^{7}$ e a observarem os direitos assegurados na Lei Maior do País, que não poderiam ser restringidos, embora fossem

3 A norma constitucional que determinou a unificação do processo legislativo em todas as unidades da federação (art. 13, no III, tanto da primitiva como da atual redação da Constituição Federal), a que se imprimiu celeridade incomum, merece os malores encômios, pela dinamizaçăo que introduziu naquele processo, possibilitando maior eficiência administrativa.

4 Cf. art. 188 e seu parágrafo único.

$5 \mathrm{Na}$ expressão "Direito Constitucional legislado dos Estados" incluemse, também, as normas organizacionais dos Municípios, constantes das respectivas leis orgânicas.

6 Cf. art. 200, caput.

7 Tais como: proibição de reeleição para o período imediato de ocupantes de mandatos executivos, obrigatoriedade de prestação de contas da administração, garantias ao Poder Judiciário e autonomia municipal (Const. Federal de 1946, art. 7\%, n? VII). 
ampliáveis, passou-se ao critério de só se admitir nas Cartas estaduais a garantia de direitos outorgados na Constituição $\mathrm{Fe}$ deral, sendo defeso aos Estados-membros e Municípios modi-
ficá-los ou ampliá-los.

Por força desses mandamentos constitucionais, unificadores de princípios, ficou tolhido o legislador constituinte estadual, que perdeu a autonomia de estipulação de direitos e normas organizacionais, jungindo-se às preceituações constitucionais da União, que Ihe ficou vedado modificar ou ampliar, como era costume no Direito Constitucional legislado dos Estados, 0 ral, havia levado, é bem verdade, como é do conhecimento gecias especificas excessiva liberalidade, obrigando a interferên5 . A incorislador revolucionário.?

Federal, A incorporação imediata dos princípios da Constituição dos Estados, nos coubesse, ao Direito Constitucional legislado atividade constituintes da Emenda $n$ ? 1, de 1969, cerceou a suas Leis Maiores nos Estados-membros, cuja reforma de cípios sem força cria cingiu a uma mera adaptação de prinredação da Carta As

ra observância constitucionais expressamente estabelecidas paqüência, pelos veis, já praticamente ípios, feitas as adaptações imprescindínais que essas unidesgotaram o rol de princípios constituciotando-se com a normades federativas poderiam adotar, completituição Federal.

Se não há dúvidas quanto à interpretação dos princípios dência também obrigatória, no que couber, na forma estabelevigor.

Ressalvadas as

para determina peculiaridades locais, no que for essencial feitas as necessárinstituto jurídico, toda a estruturação federal, porções, tem incides adaptações e guardadas as devidas propios, a menos que astados-membros e Municíestadual ou municipal não a

e 108 da Cr., principalmente, além do art. 200 , caput, cit., mais os arts. 10,13 titucional no 1, de 1969 . art. 6 , e o o Ato gratia, o Ato Institucional $n: 7$, de 26 de fevereiro de 1969 , 
comporte, como seria, por exemplo, o caso da dualidade cameral, só aplicável à União, ou o da tripartição de poderes, inexistente na estrutura municipal, que não tem lugar para o Poder Judiciário.

6. Vejamos os princípios de aplicação imediata, expressamente mencionados na Constituição Federal:

1 - forma republicana representativa;

2 - temporariedade dos mandatos eletivos, cuja duração não poderá exceder a dos correspondentes mandatos federais;

3 - independência e harmonia dos Poderes;

4 - garantias do Poder Judiciário;

5 - autonomia municipal;

6 - prestação de contas da administração;

7 - observância para os membros do Poder Legislativo dos impedimentos, quanto à prática de atos ou exercício de cargo, função ou emprego, nas mesmas condições vedados aos membros do Legislativo da União; ${ }^{10}$

8 - forma de investidura nos cargos eletivos;

9 - normas sobre o processo legislativo;

10 - preceitos sobre elaboração orçamentária;

11 - normas relativas aos funcionários públicos, inclusive aplicação de limites máximos de retribuição estabelecidos em lei federal, cuja competência se retirou dos Estados e Municípios; ${ }^{11}$

12 - limite dos subsídios dos deputados estaduais;

13 - normas referentes à perda do mandato de deputado federal e senador, aplicáveis aos deputados estaduais; ${ }^{12}$

14 - impedimentos aplicáveis aos membros dos Tribunais de Contas estaduais, cujo número máximo de componentes se fixou em sete. ${ }^{13}$ e 14

10 Cf. Const. Federal, art. 10, n? VII, e 13, n? I, que abrange os casos enumerados de 1 a 7 .

11 Const. Federal, art. 13, n? V.

12 No que concerne aos vereadores, não se aplicam as normas do art. 35 da Const. Federal, mas disposições do Decreto-lei federal $n$ ? 201, de 27 de fevereiro de 1967 , art. $8^{\circ}$, e da Lei Orgânica dos Partidos Políticos (Lei n? 5.682, de 21-7-1971), art. 72 .

13 Ver Const. Federal, art. 114, nọs I a III. Federal.

14 As normas dos nọs 8 a 14 se acham expressas no art. 13 da Const. 
15 - aplicabilidade aos funcionários estaduais e municipais de toda a seção da Constituição Federal relativa aos fun-
cionários públicos ${ }^{15}$

Esses os princípios de incidência imediata, expressamente indicados no texto constitucional, para aplicação aos Estadosmembros e que, como já se disse e resulta evidente, não oferecem dificuldades de exegese, por força da menção específica. ${ }^{16}$

7. Os princípios não expressos, por conseguinte não cuntidos na enumeração acima, mas que, igualmente, passaram a ter incidência imediata aos Estados-membros e Municípios, ex vi do art. 200, caput, da Carta Política de 1967, após o juízo de aplicabilidade decorrente da cláusula "no que couber", se resumem a três, feitas as adaptações que se impõem:

Casa Legislativa; ${ }^{17}$ duração do mandato de Mesa Diretora de

15

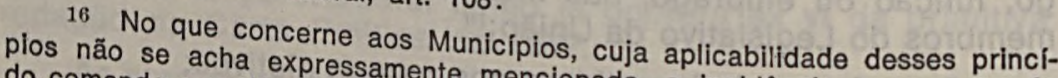

Cf. Const. Federal, art. 108. do comando constitutupressamente mencionada, a incidência ocorre através adaptaçōes. Assim, tiranl constante do art. 200, caput, feitas as necessárias tuação mesma do Município as normas de evidente inaplicabilldade, pela siquia, ou por haver regulacăấ que é uma entidade federada de menor hierarimprescindiveis adaptaçōes tederal especifica, todas as demais, feitas as aplicam a referente ao Pode têm inteira aplicação. Entre elas, pois, não se bunal de Contas, que só ser Judiciário, inexistente nos Municípios, ao. Trideral, art. 191), bem como mantém no Municipio de São Paulo (Const. Feregula pelo Decreto-lei no as normas referentes à perda do mandato, que se

desse precost. Federal, art. 30, parágrafo único, alínea h. A conciliabillidade a aplicabilidade do Legislativo municipal é absoluta, pelo que é evidente Constituição do Estado de Emenda Constitucional de Minas Gerais, após a adaptação decorrente da ano esse mandato. o que 1, de 1969, no seu art. 155, caput, fixou em um pelas Câmaras Municipais, inconstitucional, embora tenha de ser observado na Const. Federal, essa inconquanto não for declarada, na forma prevista pio, como já acentuamos, só octitucionalidade. A inaplicabilidade do princiso verifica. eleição, isto muito se tem discutido sobre obrange a alcance da proibição de re-
Diretora, ou se tấo-somentaçăo, de um modo geral, na Mesa
dacăo, dação de reeleição só licito vir o representante alcança a recondução para o mesmo cargo, sendo guinte. É que, não havento ocupar outro na mesma Mesa, na elelçăo seminado cargo" na Mesa, só mandato de "membro da Mesa", mas de "detera investidura se efetivar para ocorrerá reelelção, vale dizer, nova eleição, se blvel o rodizio, só sendo vedada asmo mandato. Assim, é perfeitamente ca- 


\section{2 - as normas relativas à convocação de suplentes, ${ }^{18} \mathrm{e}$}

3 - a criação de cargos e fixação dos respectivos vencimentos nos serviços das secretarias das Assembléias legislativas e das Câmaras Municipais, através de lei, em vez de resolução. ${ }^{19}$

8. Aliadas essas disposições decorrentes da exegese do art. 200, caput, da Constituição Federal com as normas expressas constantes dessa mesma Carta Política, verifica-se, sem sombra de dúvida, uma perfeita unificação de princípios constitucionais em todas as unidades da Federação, com o que se cerceia a autonomia dos Estados-membros e, também, a dos Municípios em que estes se subdividem, para obter-se essa centralização, o que poderia parecer não muito compatível com - Estado federal. É que a federação não é forma ideal de Estado para os países que não alcançaram seu pleno desenvolvimento, seja econômico, seja cultural, pela falta de condições de viabilidade de auto-organização e administração.

18 Const. Federal, art. $36, \S 1$. Não há razão para excluir-se a incidência dessa norma aos vereadores, de modo que a convocação de suplente só poderá ocorrer em virtude de morte, renúncia ao mandato ou investidura em função correspondente à de Secretário de Estado, equivalendo à renúncia, para esse efeito, a vaga decorrente da perda de mandato por infidelidade partidária (Lei Orgânica dos Partidos Políticos, art. 72, parágrafo único). Merece censura, ao propósito, o disposto no art. 23 da Lei Orgânica dos Municípios do Estado de São Paulo (Decreto-lei Complementar n? 9, de 31 de dezembro de 1969), que determina a convocação de suplente no caso de licença, o que se constitui em flagrante inconstitucionalidade. A únificação dos princípios constitucionais por força de normas expressas no texto constitucional e em decorrência do citado art. 200, caput, da nossa Lei Maior só permite a não-incidência destes quando se comprove a impossibilidade de aplicação, por incabivel. Por que seriam inaplicáveis aos Municípios as normas referentes à convocação de suplentes?

19 Const. Federal, arts. 40, n? III, e 42, n? IX.

As Casas Legisaltivas, por força desses dispositivos Constitucionais, combinados com o citado art. 200, caput, da mesma Carta Política, na redação em vigor, perderam a competência privativa para criar cargos e fixar os respectivos vencimentos nos seus serviços, carecendo esses atos de lei, com o que também participa o Poder Executivo, através da competente sanção. Essa providência se impunha para garantir a executoriedade do princípio da paridade, expresso no art. 98, caput, da Const. Federal; do contrário, a preceituaçăo se converteria em letra morta, pela impossibilidade de controle pelo Poder Executivo correspondente. 


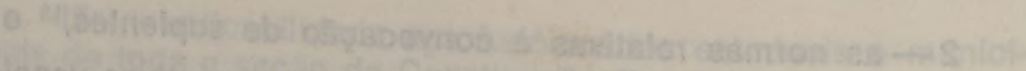

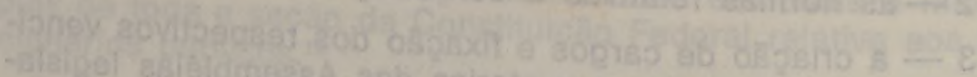

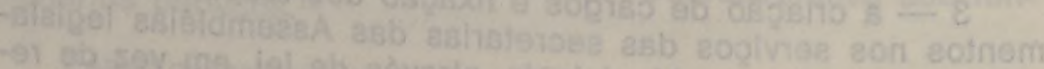

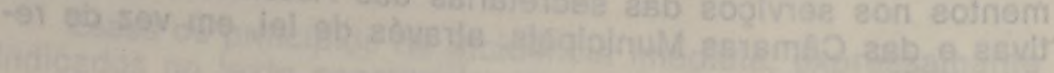
Nhosoloto

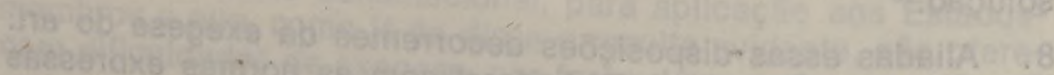

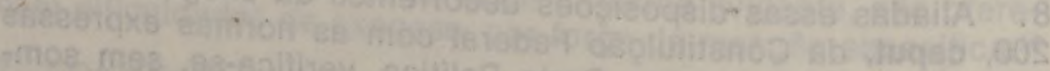

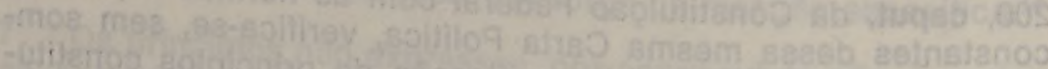

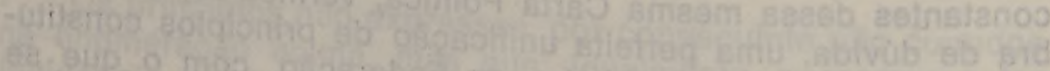

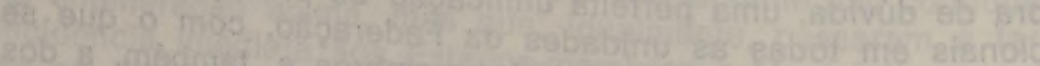

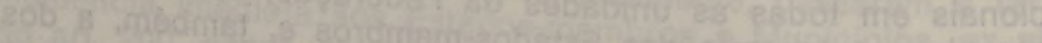

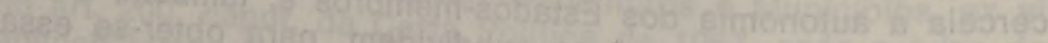

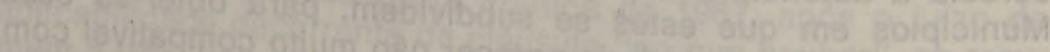

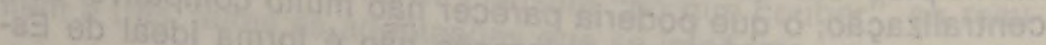

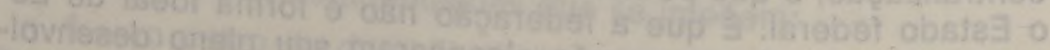

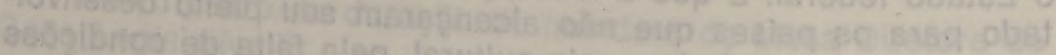

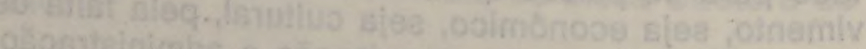

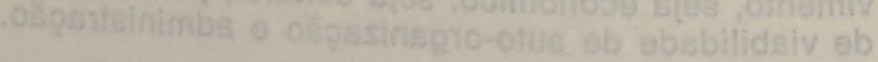

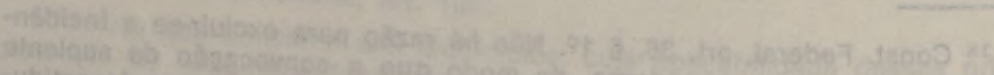

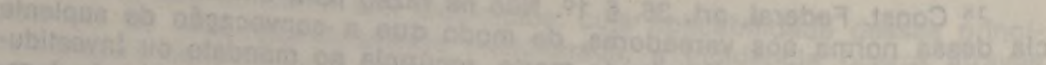

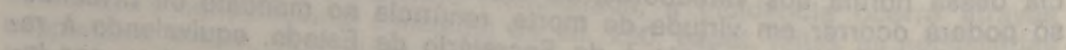

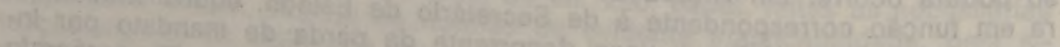

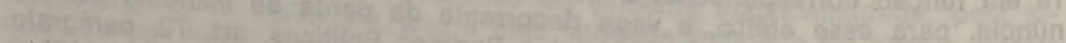

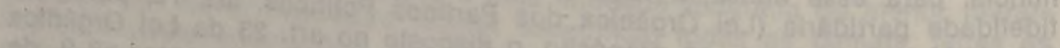

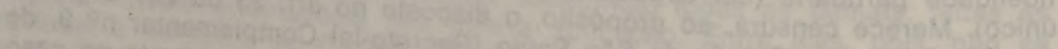

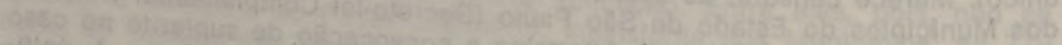

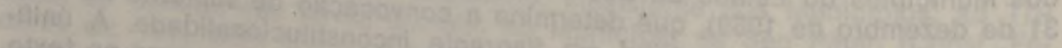

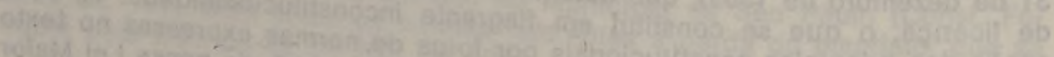

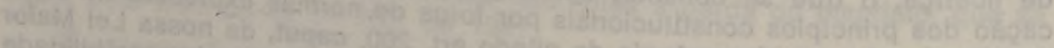

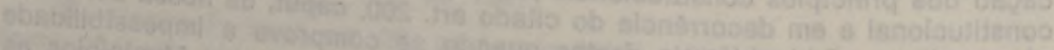

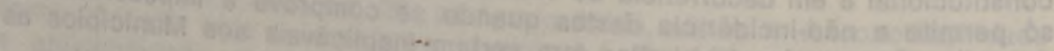

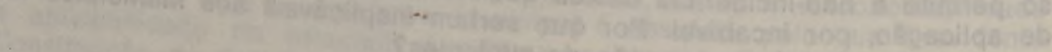
- 20.900

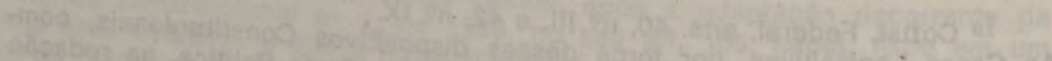

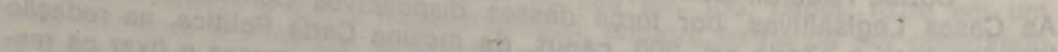

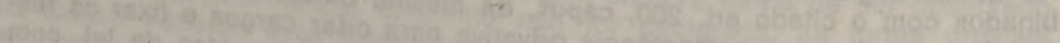

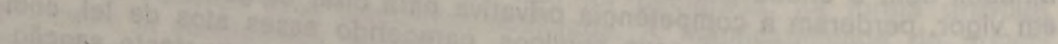

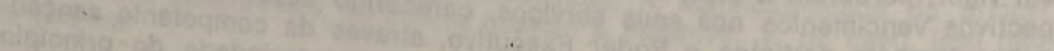

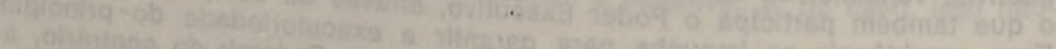

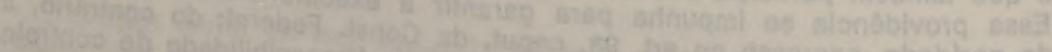

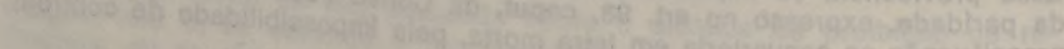

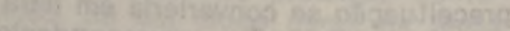

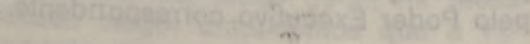

